\title{
Effect of designing Educational Program on Nurses` Performance for Immediate care of post cystectomy Patients at Intensive Care Unit
}

\author{
Eman H. Hassanein ${ }^{1}$, Medhat A. El-Hawary ${ }^{2}$, Mervat A. Abdel-Aziz ${ }^{3} \&$ Mogedda M. Mehany ${ }^{4}$. \\ Specialist Nursing at Urology Hospital, Assuit University, Egypt. \\ 2. Professor of Urology Medicine, Faculty of Medicine, Assuit University, Egypt. \\ 3. Assistant Professor of Critical Care and Emergency Nursing, Faculty of Nursing Assuit University, Egypt. \\ 4. Assistant Professor of Critical Care and Emergency Nursing, Faculty of Nursing, Assuit University, Egypt.
}

\begin{abstract}
Background: Educational program today is very important for the nurses to increase knowledge and practice for immediate care of cystectomy.Aim to: evaluate the effect of educational program on nurses` knowledge and practice for immediate care of post cystectomy patients at intensive care unit. Research design : A quasi experimental design was conducted to achieve the aim of the study. Subjects: All available nurses' were 40 nurses caring for patients with cystectomy. Two tools were used for data collection, tool one, knowledge assessment structured interviewing questionnaire and tool two, an observational checklist. Results: Nurses` knowledge scores improved after implementation of the educational program from (15\% to $97.5 \%$ ), also the observed nurses` practice scores were improved from (20\%) before the educational program to (100\%) after the educational program .Conclusion: Nurses` knowledge and practice regarding the immediate care of patients with cystectomy becomes satisfactory level after the educational program. Recommendations: The study recommends focused on establishing plans by periodical educational programs for nurses to help them in improving their knowledge and practice.
\end{abstract}

\section{Keywords: Cystectomy. Educational Program, Immediate Care, Intensive Care Unit \& Practice.}

\section{Introduction}

Bladder cancer is one of the most common disease is treated by the urologists .In men, it is the fourth most common cancer after prostate, lung, colorectal cancer .while in females it is the eight most common cancers it is the second most commonly occurring genitourinary cancer, In Egypt at 2017,agestandardized incidence in Egypt rates per100,000 were166.6(both 157.0(females). Naqib et al., (2018)

Bladder cancer involves a "malignant" or "cancerous" growth or tumor in the urinary bladder. Additional tests are usually required to determine if the cancer has spread out of the bladder ReRichards, (2017)

Cystectomy removes the bladder as well as other pelvic organs or structures. cystectomy surgical procedure that removes all or part of the urinary bladder muscular organ that collects urine from the kidneys for excretion at late time. Samineni et al., (2017)

The main high risk factors for bladder cancer are; Aging : elderly people .overall $70 \%$ of patients developing bladder cancer are diagnosed after the age of 65, Previous history of bladder cancer Cigarrete smoking :is the most important risk factor for bladder cancer, Irradiation :exposure to ionizing irradiation in the region of bladder for example during radiotherapy for prostate, Body that being over weight is associated with ahigher risk of bladder cancer and Anumber of chemicals have been identified that may cause bladder . pstein,(2016)

Signs \& Symptoms of bladder cancer ;hematuria ,pain during urination, urinating small amounts frequently and Frequent urinary tract infection ReRichards, (2017)

Complications of cystectomy includes gastrointestinal infection, urinary leakage, urinary tract infection ,post-operative haemorrhage requiring 4 units within 72 hours post operatively, deterioration in renal function, calculi formation, metabolic complications, voiding dysfunction, urinary retention, bowel or urine leaking from where they were joined together, injury to the bowel, major blood vessels and nerves, bowel injury requiring bowel diversion and recurrence of the disease needing another surgery woodruff,(2016)

Immediate post operative care, the bed will be booked for the patient in the intensive care unit (ICU) where patient's condition can be monitored closely .To reduce pain after the operation the patient will be given regular analgesic through An epidural by which analgesic and local anaesthetic are given directly into the spinal nerve system. After a few days the need for these drugs will have reduced greatly and then be given analgesics tablets or injections. ReRichards, (2017) .

The fluids will be given until the patient is able to 
drink normally accurate measuring and recording of intake and urinary output from each catheter, Fluid intake after surgery should be at least $2000 \mathrm{ml}$ per day . The passage of wind via the rectum is the sign that things are returning to normal but the patient can usually start to have fluids within a day or two of the operation and start diet within 2 days. The patient will have a dressing over the wound on the abdomen should be checked. Assess size, color, and condition of the stoma and surrounding skin every 2 hours for the first 24 hours, then every 4 hours for 48 to 72 hours. Samineni et al., (2017)

Nursing care of cystectomy The nurse should be checked the wound every dressing and report any local signs of infection The nurse must measure auxiliary temperature every four hours and monitor the blood pressure, pulse, and respiratory rate according to the physicians order. Urden, (2016).

These findings should be reported immediately to physician. Also the nurse must follow the aseptic technique in dressing on the wound or the drain and give patient prescribed antibiotics, leg exercise and early ambulation particularly important for the patient with cystectomy, because of lymph nodes removal and the tendency to develop congestion and edema , bowel sounds and motility should return in 3-5 days after surgery, monitor blood urea nitrogene, creatinine values, electrolytes balance should be assessed by daily laboratory data Urden,(2016)

Nurses are in the key position to carry out health care. Health care providers who have continuous contact with patients and their families and have the opportunities to assess potential problems, specific care for patient and give teaching about all aspects of care Garris, (2014).

Educational program today is very important for the nurses to increase knowledge and practice about cystectomy care, to help them to assess patient status and determine any complication which may be occur for the patient and how to treat and prevent these complications and learn the specific care for this patient Woodruff,(2016).

Nursing staff are in need for continuous training and for applying this training to improve the standard of patient care The educational program is considered to be an important means to provide nurses with theoretical and technical information needed to acquire skills and competencies necessary to continually improve nursing practice .The educational program is designed to assist health worker to maintain and improve their competencies and to acquire knowledge. urden et al., (2016).

\section{Significance of the Study}

Nurses should have knowledge, good practice and be skillful in dealing with immediate care of cystectomy, so there is a need for this study to reduce the prolonged patient staying at the urological ICU due to surgical site infection(SSI) through promoting nurses' knowledge that could help them to contribute a successful patients' care and through also nurses' practice by using a septic technique in the wound care. Garris,(2014)

Showed that more than $70 \%$ of cases of cystectomy delaying of healing and there was relationship between prolonged patient staying and lack of knowledge and practice of nurses Regarding baseline about wound care, showed that all studied nurses did not assess wound and surrounding skin to determine wound stage or inspect dressing. And not report any unusual findings immediately.Statistical reports of urological intensive care unit at Assuit university hospital documented that in (2015-2016) 70 cases diagnosed with cystectomy.

\section{Aim of the Study}

This study aimed to evaluate the effect of educational program on nurses knowledge and practice for immediate care of post cystectomy patients at intensive care unit.

\section{Research Hypothesis}

1. The mean total knowledge and practice score will improve after the educational program.

2. The following research hypothesis were formulated in an attempt to achieve the aim of the study

3. A positive relationship will exist between knowledge and skills scores obtained by the critical care nurses after receiving the educational program

\section{Subject \& Methods \\ Research design}

Study variables: the independent variable in this study was the educational program for the nurses ,the dependent variable was the nurses performance A quasi experimental research design (pre-posttest), was utilized to achieve the aim of the study.

A design of one group pre/ posttest was used .

\section{Setting}

This study was carried out at urological intensive care unit at Assuit university hospital.

\section{Sample}

All available nurses (40) who provided direct nursing care for patients admitted to the urological ICU.

Tools

Two tools was developed by the researcher based on the related literatures was used to collect data.

Tool: Structured Interviewing questionnaire This tool developed by the researcher after reviewing the literature to assess nurses` knowledge about cystectomy management it includes two parts

Part 1: Demographic data: consist of (age, gender, qualification and years of experience ). 
Part 2: self-administered questionnaire Sheet: consist of (Definition, high risk factors, signs\& symptoms of bladder cancer, immediate care, complications , nursing care for reducing complications of cystectomy ).

\section{Scoring system}

Each correct answer was given one score, the number of questions was 25. The total score of the questionnaires was less than $(60 \%)$ were considered unsatisfactory level. While those who obtained $(60 \%)$ or above were considered satisfactory according to the range of the total scores, it laid between (0-50 degrees).

Tool II: Nurses` practice (observational checklist): This tool developed by the researcher after reviewing the literature used to assess nurses ' practice by using observational check list about cystectomy immediate post care such as nursing Care for the patient during urological intensive care unit.

The observation checklist was developed to assess the practical aspects of the basic nurses' procedure about care of patient of cystectomy as the following:-

Oxygen therapy, For extubation, Pulse oximetry, Arterial blood gases, Central venous measurements, Infusion pump, Plasma transfusion, Wound care, Body mass index and Assessment of complications Scoring system: Each step was observed, categorized and scored as follow: two degrees for each step that was done correct, one degree for each step done but incorrect method and zero for step that was not done. The total score for all the steps was less than $(60 \%)$ were considered inadequate practical level. $(60 \%)$ or above were considered adequate practical level.

\section{Methods}

\section{Preparatory phase}

An Approval to conduct the study Official permission to conduct the study obtained from the hospital responsible authorities in the emergency medical unit after explaining the aim and the nature of the study. The tools used in this study were developed by the researcher based on reviewing the relevant literature.

Tools \&reliability: The tools was tested for content of validity by jury of 5 experts in the field of critical care nursing and critical care medicine from a suit university hospital ,the necessary modifications were done.

The reliability was tested by using Cronbach coefficient alpha. tool I (knowledge assessment tool) the program success in improving knowledge scores of nurses who were which was (0.58) and tool II practice scores was $(0.86)$ which was acceptable tool two ( practice assessment tool)

A pilot study was conducted on 5 nurses to test the feasibility and applicability of the tools.

\section{Ethical consideration}

1) Research proposal was approved from ethical committee in the faculty of nursing.

2) There was no risk for study subject during application of the research.

3) The study followed common ethical principles in clinical research.

4) Informed consent was taken from person participating study after explaining the nature and purpose of the study.

5) Data was assured confidentiality and anonymity.

6) Study subject privacy was considered during data collection.

The program passed through four phases

Assessment phase: upon finalization of the tools and getting official permission the researcher stated to assess nurses` knowledge by using structured interviewing questionnaire questionnaire sheet this followed by observing their practice in different shift using the observational checklist.

Planning phase: based on analysis of the collected data and using pertinent literature the researcher developed an educational program in form of hand out booklet in Arabic language. The objective of the program was to improve nurses, knowledge and practice regarding of patients with cystectomy the program was developed to cover all necessary knowledge and practice needed proper practice.

Implementation phase : Implementation of the educational program took weeks. The program was applied for all nurses working in intensive care unit, it was not applicable for all nurses attend an .educational session at the same time, so they was divided into groups 3-5 according to their work schedule. The program covers two parts:

Theoretical part which include:

a- First session lasted for (30 $\mathrm{min}$ ) included: anatomy, function of the bladderand short note about cystectomy in general.

b- Second session lasted for (1 hour) which included: definition, high risk factors and immediate care.

c- Third session lasted for (1 hour) which included:Indications and complications.

d- Forth session lasted for (1 hour) which included: Nutrition, and nursing role.

\section{Practical part}

In these section (practical part ) which was lasted for 2 hours each nurse demonstrated and re-demonstrated the step of each procedure individually under supervision of the researcher (oxygen therapy ,extubation, Pulse oximetry , arterial blood gases central venous pressure, infusion pump ,plasma transfusion, wound care, body mass index and assessment of complications). 


\section{Learning environment}

The program was applied in a class room at Intensive Care Unit.

Teaching methods .Lectures, brain storming, discussion, demonstration

and remonstration Media used: Hand out, poster and demonstration

equipment.

\section{Evaluation phase}

All nurses were evaluated one time after assessment The evaluation of program was carried out twice, preimplementation of program and immediately after the application of the program using the pre-test study tools one and two in order to test the effectiveness of the program on nurses' knowledge and practice.

\section{Statistical analysis}

Data entry was done and data analyzed, categorized and then coded, were done with the IBM SPSS 20.0 software. The data were tested for normality using the Anderson-Darling test and for homogeneity variances prior to further statistical analysis. Categorical variables were described by number and percent $(\mathrm{N}$ $\%$ ), where continuous variables described by mean and standard deviation (Mean, SD). Chi-Square test and fisher exact test used to compare between categorical variables where compare between continuous variables by T-test and ANOVA Test. A two-tailed $\mathrm{p}<0.05$ was considered statistically significant. We are used person Correlation to Appear the Association between scores.

\section{Results.}

Table (1): Frequency distribution for nurses` demographic characteristics of the studied nurses $(\mathrm{No}=40)$.

\begin{tabular}{|l|c|c|}
\hline \multicolumn{1}{|c|}{ (No= 40) } & \% \\
\hline Age: (years) & \multicolumn{2}{|c|}{$23.70 \pm 3.71$} \\
\hline Mean \pm SD & \multicolumn{2}{|c|}{$20.0 \pm 45.0$} \\
\hline Range & 3 & \\
\hline Qualification: & 9 & 7.5 \\
\hline Nursing secondary school & 28 & 22.5 \\
\hline Technical nursing institute & & 70.0 \\
\hline Nursing Bachelor & 31 & 77.5 \\
\hline Years of experience: & 2 & 5.0 \\
\hline $1-<3$ & 3 & 7.5 \\
\hline $3-<5$ & 4 & 10.0 \\
\hline $5-10$ & & 100.0 \\
\hline$>10$ & 40 & 0.0 \\
\hline Gender & 0 & \\
\hline Female & 3 & \\
\hline Male & \multicolumn{2}{|c|}{} \\
\hline
\end{tabular}

Data described as (mean $\pm S D)$ independent sample t-test

Table (2) Mean of nurse's knowledge score pre \&post implementation of educational program

\begin{tabular}{|l|c|c|c|c|}
\hline \multicolumn{1}{|c|}{ Nurses`Knowledge } & \multirow{2}{*}{$\begin{array}{l}\text { Max. } \\
\text { score }\end{array}$} & $\begin{array}{c}\text { Pre-test } \\
(\mathbf{n = 4 0 )}\end{array}$ & $\begin{array}{c}\text { Post-test } \\
(\mathbf{n = 4 0})\end{array}$ & \multirow{2}{*}{ P-value } \\
\cline { 3 - 5 } & & Mean \pm SD & Mean \pm SD & \\
\hline Definition of cystectomy & $\mathbf{2}$ & $0.72 \pm 0.34$ & $1.56 \pm 0.59$ & $0.001^{*}$ \\
\hline High risk factors cystectomy & $\mathbf{3}$ & $1.84 \pm 0.71$ & $3.87 \pm 1.33$ & $0.001^{*}$ \\
\hline Signs and symptoms of bladder cancer & $\mathbf{4}$ & $2.48 \pm 0.60$ & $4.83 \pm 01.53$ & $0.001^{*}$ \\
\hline Complications & $\mathbf{4}$ & $2.48 \pm 0.60$ & $4.83 \pm 01.53$ & $0.001^{*}$ \\
\hline Immediate post-operative care & $\mathbf{6}$ & $1.97 \pm 0.54$ & $5.09 \pm 1.27$ & $0.001^{*}$ \\
\hline nursing care of cystectomy & $\mathbf{6}$ & $2.43 \pm 0.87$ & $4.85 \pm 1.36$ & $0.001^{*}$ \\
\hline Total score of knowledge & $\mathbf{2 5}$ & $11.09 \pm 3.66$ & $20.18 \pm 7.61$ & $0.001^{*}$ \\
\hline
\end{tabular}

*statistically significant difference ( $p<0.05)$ Data described as (mean $\pm S D$ ) independent sample t-test and ( $n \& \%)$ chi-Square 
Table (3): Mean nurse's practice scores pre \&post implementation of educational program.

\begin{tabular}{|l|c|c|c|c|}
\multicolumn{1}{|c}{ Nurses' practice } & \multirow{2}{*}{$\begin{array}{c}\text { Max. } \\
\text { score }\end{array}$} & $\begin{array}{c}\text { Pre-test } \\
(\mathbf{n = 4 0})\end{array}$ & $\begin{array}{c}\text { Post-test } \\
(\mathbf{n = 4 0})\end{array}$ & \multirow{2}{*}{ P-value } \\
\cline { 3 - 5 } & & Mean \pm SD & Mean \pm SD & \\
\hline Oxygen therapy & $\mathbf{1 4}$ & $10.22 \pm 2.20$ & $13.53 \pm 0.72$ & $0.001^{*}$ \\
\hline For estuation & $\mathbf{1 2}$ & $4.40 \pm 1.66$ & $9.87 \pm 1.30$ & $0.001^{*}$ \\
\hline Pulse oximetry & $\mathbf{8}$ & $6.00 \pm 1.50$ & $7.55 \pm 0.85$ & $0.001^{*}$ \\
\hline Arterial blood gases & $\mathbf{2 0}$ & $9.82 \pm 2.91$ & $16.45 \pm 2.07$ & $0.001^{*}$ \\
\hline Central venous measurements & $\mathbf{1 6}$ & $11.85 \pm 2.54$ & $15.05 \pm 1.01$ & $0.001^{*}$ \\
\hline Infusion pumps & $\mathbf{2 2}$ & $11.23 \pm 2.26$ & $17.53 \pm 2.43$ & $0.001^{*}$ \\
\hline Plasma transfusion & $\mathbf{2 2}$ & $11.20 \pm 2.58$ & $18.92 \pm 1.75$ & $0.001^{*}$ \\
\hline Wound care & $\mathbf{2 8}$ & $13.80 \pm 4.28$ & $24.83 \pm 1.93$ & $0.001^{*}$ \\
\hline body mass index & $\mathbf{2}$ & $0.00 \pm 0.00$ & $1.80 \pm 0.41$ & $0.001^{*}$ \\
\hline Assessment of complications & $\mathbf{1 4}$ & $2.72 \pm 1.71$ & $12.00 \pm 1.30$ & $0.001^{*}$ \\
\hline
\end{tabular}

*statistically significant difference $(p<0.05)$

Data described as (mean $\pm S D)$ independent sample t-test and ( $n \& \%)$ chi-square.

Table (4): Relationship between knowledge score and nurse`s demographic data for pre\& posttest of educational program

\begin{tabular}{|c|c|c|c|c|}
\hline & \multicolumn{4}{|c|}{ Knowledge score } \\
\hline & Pre-test & \multirow{2}{*}{ P-value } & Post-test & \multirow{2}{*}{ P-value } \\
\hline & Mean \pm SD & & Mean \pm SD & \\
\hline \multicolumn{4}{|l|}{ Age: (years) } & \multirow{3}{*}{0.916} \\
\hline$<25$ & $20.34 \pm 9.63$ & \multirow[t]{2}{*}{$0.029 *$} & $44.91 \pm 6.06$ & \\
\hline$\geq 25$ & $30.80 \pm 9.83$ & & $44.60 \pm 7.13$ & \\
\hline \multicolumn{2}{|l|}{ Qualification: } & \multirow{4}{*}{$0.021 *$} & & \multirow{4}{*}{0.808} \\
\hline Nursing Secondary School & $30.00 \pm 9.54$ & & $47.00 \pm 5.57$ & \\
\hline Technical Nursing Institute & $27.67 \pm 9.90$ & & $45.11 \pm 5.04$ & \\
\hline Nursing Bachelor & $18.82 \pm 9.21$ & & $44.57 \pm 6.59$ & \\
\hline \multicolumn{2}{|l|}{ Years of experience: } & \multirow{5}{*}{0.135} & & \multirow{5}{*}{0.846} \\
\hline $1-<3$ & $19.65 \pm 9.96$ & & $44.71 \pm 6.27$ & \\
\hline $3-<5$ & $26.50 \pm 3.54$ & & $46.00 \pm 4.24$ & \\
\hline $5-10$ & $28.33 \pm 11.85$ & & $43.00 \pm 9.00$ & \\
\hline$>10$ & $29.75 \pm 7.80$ & & $47.00 \pm 4.55$ & \\
\hline \multicolumn{5}{|l|}{ Gender } \\
\hline Female & $20.34 \pm 9.63$ & $0.029 *$ & $44.91 \pm 6.06$ & 0.916 \\
\hline Male & $30.80 \pm 9.83$ & & $44.60 \pm 7.13$ & \\
\hline
\end{tabular}

*statistically significant difference ( $p<0.05)$ Data described as (mean $\pm S D)$ independent sample t-test and $(n \&$ \%) chi-square.

Table (5): Relationship between practice score and nurse`s demographic data for pre\& posttest of educational program.

\begin{tabular}{|c|c|c|c|c|}
\hline & \multicolumn{4}{|c|}{ Performance score } \\
\hline & Pre-test & \multirow{2}{*}{$\begin{array}{c}\text { P- } \\
\text { value }\end{array}$} & Post-test & \multirow{2}{*}{ P-value } \\
\hline & Mean \pm SD & & Mean \pm SD & \\
\hline \multicolumn{4}{|l|}{ Age: (years) } & \multirow{3}{*}{$0.007^{*}$} \\
\hline$<25$ & $79.57 \pm 8.10$ & \multirow[t]{2}{*}{$0.000 *$} & $138.34 \pm 5.94$ & \\
\hline$\geq 25$ & $103.60 \pm 15.01$ & & $146.00 \pm 1.58$ & \\
\hline Qualification: & & \multirow{4}{*}{$0.003 *$} & & \multirow{4}{*}{$0.004 *$} \\
\hline Nursing Secondary School & $102.67 \pm 20.55$ & & $145.33 \pm 1.53$ & \\
\hline Technical Nursing Institute & $85.33 \pm 10.59$ & & $143.44 \pm 5.32$ & \\
\hline Nursing Bachelor & $79.54 \pm 9.38$ & & $137.32 \pm 5.64$ & \\
\hline
\end{tabular}




\begin{tabular}{|c|c|c|c|c|}
\hline & \multicolumn{4}{|c|}{ Performance score } \\
\hline & Pre-test & \multirow{2}{*}{$\begin{array}{c}P- \\
\text { value }\end{array}$} & Post-test & \multirow{2}{*}{ P-value } \\
\hline & Mean \pm SD & & Mean \pm SD & \\
\hline \multicolumn{4}{|c|}{ Years of experience: } & \multirow{5}{*}{$0.047 *$} \\
\hline $1-<3$ & $80.13 \pm 8.55$ & \multirow{4}{*}{$0.014 *$} & $138.16 \pm 5.69$ & \\
\hline $3-<5$ & $94.00 \pm 16.97$ & & $145.50 \pm 0.71$ & \\
\hline $5-10$ & $79.67 \pm 17.95$ & & $138.33 \pm 10.02$ & \\
\hline$>10$ & $98.00 \pm 19.20$ & & $145.75 \pm 1.50$ & \\
\hline \multicolumn{2}{|l|}{ Gender } & \multirow{3}{*}{$0.000 *$} & & \multirow{3}{*}{$0.007^{*}$} \\
\hline Female & $75.57 \pm 7.10$ & & $118.34 \pm 3.94$ & \\
\hline Male & $101.60 \pm 13.01$ & & $126.00 \pm 1.38$ & \\
\hline
\end{tabular}

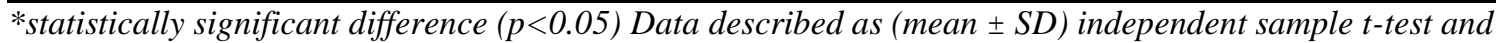
(n\&\%) chi-square

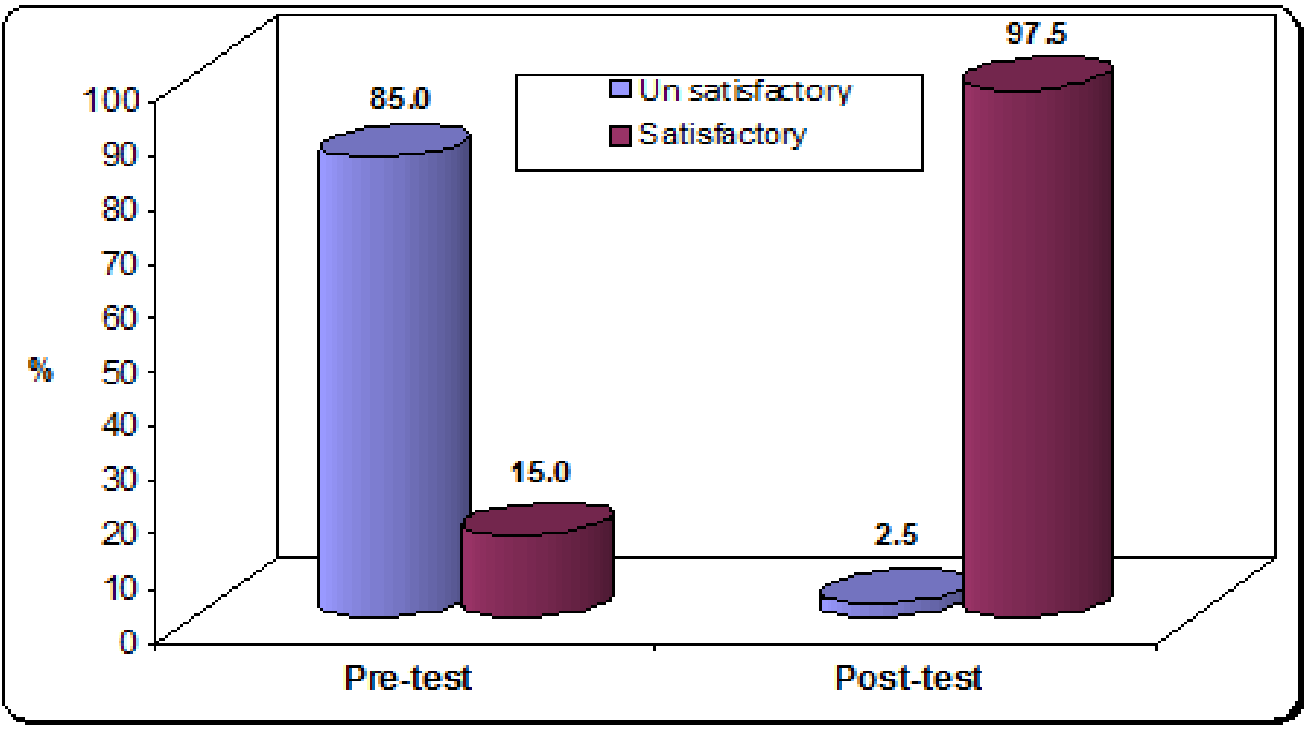

Figure (1): percentage distribution of the studied nurses regarding the knowledge level.

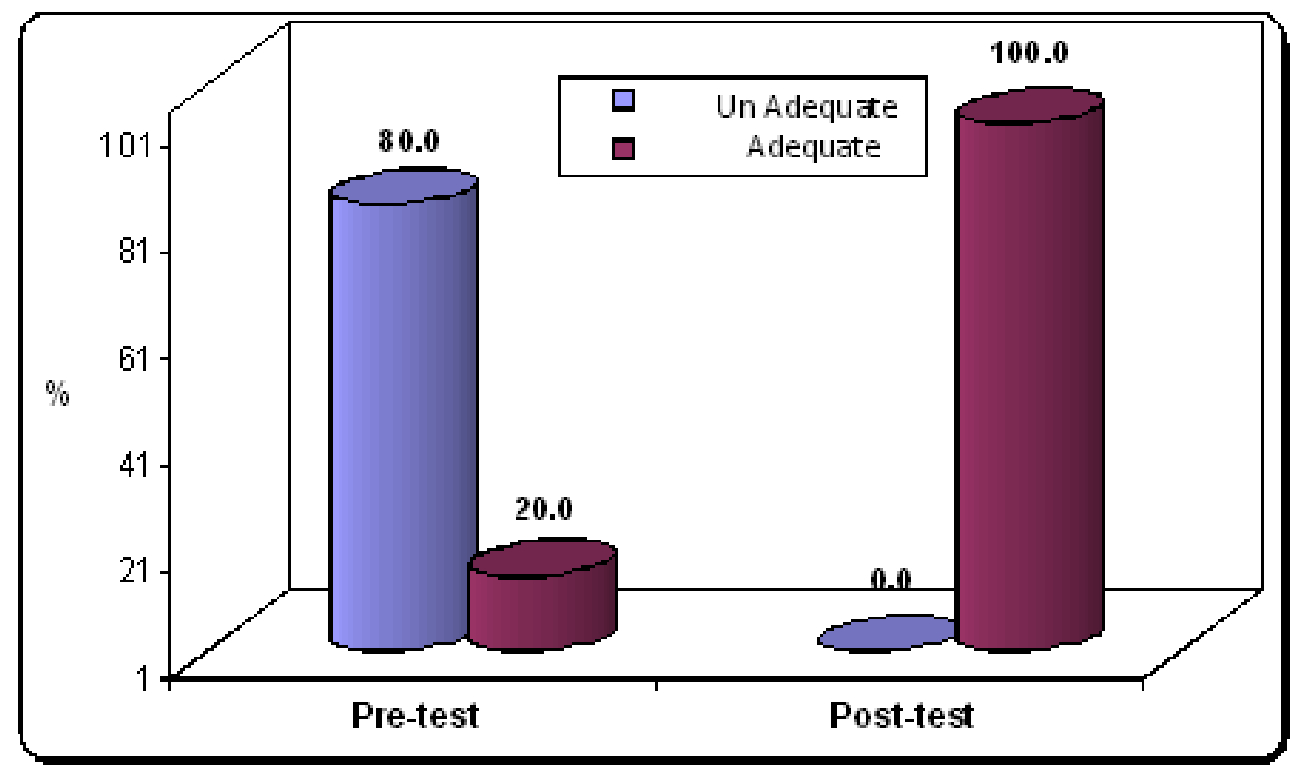

Figure (2): percentage distribution of the studied nurses regarding the practice level. 
Table (1): This table shows that; Concerning their educational level $(70 \%)$ of the nurse held Bachelor of nursing; $(22.50 \%)$ of the nurse held technical institute of nursing and $(7.5 \%)$ of the nurse held 3 years nursing diploma, Moreover, $(77.50 \%)$ of nurse had work experience less than 3 years and (10.0\%) of them had more than or equal 10 years. this table reveals that $(100.0 \%)$ of them were females.

Table (2): This table shows that mean scores for each domain of knowledge, there is a highly significant statistically differences $(\mathrm{P}=0.000)$ in nurses knowledge in comparison between pre and post implementation of the teaching program .

Table (3): This table shows that Mean scores for each domain of performance, there is a highly significant statistically differences $(\mathrm{P}=0.000)$ in nurse's practice in comparison between pre and post implementation of the teaching program.

Table (4): This table showed that there was significant statistical difference between total nurse's knowledge scores of pretest and their demographic data except years of experience there was no significant statistical difference and posttest knowledge scores. In addition there was a significant statistical difference between total nurses` practice scores of pre and posttest and the demographic data.

Table (5): This table showed that there was a significant statistical difference between total nurses practice scores of pre and posttest and the demographic data.

Fig (1): Shows there is statistically significant differences $(\mathrm{P}=0.000)$ in nurses' satisfaction in comparison between pre and post implementation of the teaching program regarding the knowledge level.

Fig (2): Shows there are statistically significant differences $(\mathrm{P}=0.000)$ in nurses' adequacy in comparison between pre and post implementation of the Educational program regarding the practice level.

\section{Discussion}

The present study aimed to evaluate the effect of educational program on nurses knowledge and practice for immediate care of cystectomy patients at intensive care unit.

This discussion was covered the main result findings as follow

From the result of the present study, it showed that there was a statistical significant difference between pre and post Education program regarding all items of cystectomy (nurses` knowledge); in addition there were a significant improvement in nurses` practice scores post application of educational program.

From the result of the present study showed that there was a statistical significant difference between before and after the Educational program application regarding wound care and plasma transfusion care.
Majority of nurses having knowledge regarding wound care, plasma transfusion care and plasma role in wound healing after education program application. Only the present study mentioned this topic. As well, showed that there was a statistical significant difference between degree of total nurses' practice score before and after education program in the present study

The current study revealed a great improvement in their knowledge about cystectomy after application of the education program. In the same line, Kaushal, (2015) emphasize the positive impact of a training program on the knowledge scores hence the healthcare organizations can engage in continuous training programs to regularly maintain and enhance the knowledge of the nurses. Also, Cooper, (2019) found that; technique, A pre- and post-test were administered; the mean pretest score was $72.1 \%$ and the mean posttest score was $94.1 \%$. Comparison of pre- and post-test scores reflect a $22 \%$ increase in test scores, therefore, this program increased knowledge. This project can contribute to positive social change by improving nursing practice through increasing nurses' knowledge of proper care of cystectomy, which can translate into evidence-based practice changes and improve patient outcomes.

Regarding baseline nurses practice about care of plasma transfusion, showed that majority of studied nurses did not obtain patient's vital signs, including temperature, didn`t know If adverse reactions occur, close clamp to plasma and notify physician. . In addition, most of them did not perform neither confirm the order for plasma transfusion in the medical record nor documented that, Urden et al., (2016) emphasized in their study that the importance of plasma transfusion in the healing of the wound of cystectomy, so the nurse should monitor patients vital signs specially temperature in addition to if adverse reactions occur, close clamp to plasma and notify physician. Confirm the order for plasma transfusion in the medical record and documented that.

Regarding baseline nurses practice about wound care, showed that all studied nurses did not introduce self and verify patient's identity, explain procedure to the patient, assess wound and surrounding skin to determine wound stage or inspect dressing and exposed wound observing or drainage, foul odor, and tissue necrosis. And not report any unusual findings immediately.

The exciting study showed that there was significant statistical difference between total nurse's knowledge scores of pretest and their demographic data except years of experience there was no significant statistical difference and posttest knowledge scores. In addition there was a significant statistical difference between total nurses practice scores of pre and posttest and 
their demographic data this agreed with. Bayoumi, (2017) revealed that no significant difference between nurses practice scores with their years of experience observed during pre-test.

There were some main items as regard nurses activities for patient post cystectomy were poor knowledge for most nurses. These items include. ( check level of consciousness, measurement of centeral venous pressure ,care of plasma transfusion and check the dressing) In the same line Sharaf, (2018) who stated that There were some main items as regard nurses activities for patient post cystectomy are neglected from most nurses. These items, include, check level of consciousness, suction of endotracheal tube, check the dressing, and check the nails bed The present study revealed that The relation of age and years of experience observed during the pretest may be attributed to the transfer of inappropriate knowledge and practice from old to new nurses, who in turn lead to following the same mistakes in caring for patients agreed with Bayoumi, (2017) revealed that no significant difference between nurses` practice scores with their years of experience observed during pre-test.

And also agreed with Soaad, (2016)that revealed the adequate pre education program knowledge is statistically significant more frequently among nurses had 25-30 years as they recently graduated and had knowledge from their studies, more than 10 years of experience and who attended training courses

In regard to type of qualification, the present study shows no statistically significant among nurses had diploma ,nurses graduated in technical institute's and bachelor degree this agreed with Soaad, (2016) and agreed with Standfuss, (2012)who found that no statistically significant difference was found between educational groups in overall mean score

In this study as regards the studied nurses qualification no significant difference was found between critical care nurses level of knowledge and their qualification this not compatible with Abdul Nasser, ( 2015) who revealed that as regards the studied nurses qualification a significant difference was found between critical care nurses level of knowledge and practice and their qualification Also Abolwaf, (2013) who found that, the total scores of nurses knowledge that having diploma of secondary nursing school had significantly higher scores than those who having bachelor in nursing sciences.

In this study a significant difference was found between practice scores and their experience these results in the agreement with Abdul Nasser, (2015) also agree with the study of El- eslam, (2011)who found that nurses years of experience and their practice revealed that there was significant statistical differences
The result of the present study revealed that there was no statistical significant relationship between knowledge regarding immediate care of cystectomy in ICU and their socio demographic data this findings points successful effect of the educational program about immediate care of cystectomy to all nurses irrespective of their age years of experience level of education This result was supported by Batool, (2013 ) who reported that there was nonsignificant relationship atp-value (0.515) level between nurses knowledge and their socio demographic data and disagreed with Fayed et al., (2016) declared was highly significant difference between nurses knowledge and their socio demographic data theses in the agreement with Hayam, 2017) that revealed that there was statistically in significant relationship between knowledge in ICU and their socio demographic data The result of the present study revealed that there was statistically significant relationship between practice regarding immediate care of cystectomy in ICU and their socio demographic data this result agreed with fayed et al., (2016) declared was highly significant difference between nurses knowledge and their socio demographic data, this result disagreed with Batool, (2013 )who reported that there was non-significant relationship atp-value (0.515) level between nurses practice and their socio demographic data, also theses disagreed with Hayam, (2017) that revealed that there was statistically significant relationship between practice in ICU and their socio demographic data.

This not incompatible with Sharaf, (2018) that revealed, there was statistical significant in nurses knowledge and practice in relation to years of experience. This finding in the same line with, Naqib et al., (2018)

Who found that ; Regarding socio-demographic data of studied nurses in renal department, it was found that majority of them were in the age group from 20 to 23 years with mean age $20.06 \pm 6.07$ (21-45),

In this study $15 \%$ of the studied nurses had adequate knowledge that increased to $97.5 \%$ after the educational program, this result is supported by other studies for example Garris, (2014) in her study about nurses knowledge related to heart failure essentials at Rhode Island college found that pretest mean score was $73.3 \%$ and post education program mean score was $86.1 \%$.

Nurse plays an essential role in caring of patients of cystectomy especially in wound care. In this concern, the nurse could gain the patient cooperation by explaining the procedure and its purpose to him/her. In addition assessing wound and surrounding skin to determine wound stage or inspecting dressing and exposed wound observing or drainage, foul odor, and 
tissue necrosis and reporting all findings to the physician immediately consider the main step for early detection and management for any unexpected out comes.

Finally, the findings of the present study supported the research hypothesis that nurses in urology ICU who received the educational program about cystectomy care showed a high score of knowledge and practice after test than that before.

\section{Conclusions}

Based on the result of the present study, it can be concluded that:

There was improvement in nurses' knowledge score after introducing the educational program regarding patients with cystectomy in urological intensive care unit at Assuit university hospital

There was improvement in nurses practice score after introducing the educational program regarding patients with cystectomy in urological intensive care unit at Assuit university hospital

A positive relationship will exist between knowledge and skills scores obtained by the critical care nurses after receiving the educational program

There will be significant statistical difference in relationship between total nurses knowledge scores of pretest and demographic data except years of experience there will be no significant statistical difference and posttest knowledge scores.

There will be a significant statistical difference in relationship between total nurses 'practice scores of pre and posttest and their demographic data

\section{Recommendations}

Based on results of the present study the following can be recommended:

1. Continuous nursing education and in service training programs on urological intensive care unit should be well organized at Assuit university hospital.

2. Nurses should add to their routine work the regular reading of up-to-date references (periodical, textbooks, etc.) and encouraged to attend scientific meetings and conferences to keep pace with the rapidly growing wealth of knowledge and practice necessary for proper nursing service.

\section{References}

1. Abdel Nasser, M., (2015): Impact of educational training program on nurses' performance for patient undergoing Endotracheal tube at Assuit university Hospital master thesis critical care Nursing, faculty of Nursing Assuit university p.p 89-91.
2. Abolwaf, N., Ouda, W., Mohamed, F., \& Masoedi, F., (2013): Developing educational program for Nurses' Related to Infection of Invasive Procedures in Neonatal Units at ElMinia University \&General Hospitals, Journal of American science, p.p 287.

3. Batool A., (2013): Assessment of nurses' Knowledge concerning Glasco coma Scale In neuro surgical ,Ward Journal of Kufa for Nursing Science, Vol.(3) NO.(2).

4. Bayoumi M., Mahmoud N., (2017): Effect of education program on nurses' knowledge and practice regarding care of central venous line in pediatric hemodialysis: evidence-based practice guidelines, Egyptian Nursing Journal, Vol. 14 No. 2, P.P. :87-99.

5. Cooper, M., (2019): Improving Nurses' Knowledge of Central Line-Associated Blood stream Infection., Walden Dissertations and Doctoral Studies, Walden University scholar works), P.P:40-47

6. El- Eslam, R., (2011): Impact of Implementing infection Control program for nurses to control nosocomial infection in neonatal intensive care units port said .Alexandria Scientific Nursing Journal 12(1),p.p30-31.

7. Fayed, M., Hanan, T., ELbahnasaway, T., \& Omer, K., (2016): Effect of instructional program onNursescompliance With universal precautions of Infection Control, International Journal of novel Research in Health care and Nursing vol3, issue 1,pp(81-92)

8. Fontaine, D., Morton, P., (2013): Critical Care Nursing a Holistic Approach, Wolters Kluwer Health,pp 363-365.

9. Garris A., (2014): Nurses' Knowledge related to heart failure essentials master of science in Nursing p.p 42.

10. Hayam, M., (2017): An educational program about cell saver machine on nurses' knowledge and skills during Biliary pancreatic surgeries at Al Rajhy liver hospital .master thesis ,critical care Nursing ,faculty of Nursing Assuit university p.p(47-48).

11. Kaushal G., (2015): Impact of Training on Knowledge, Attitude and Practices Scores of ICU Nurses regarding Standard Precautions of Infection Control in a Super Specialty Hospital of Delhi, Indian Journal of Research, 4, (8), 282-285.

12. Naqib, D., Purvin, M., Prasad, R., Hanna, I., Dimitri, S., Llufrio, A., \& Hanna, M., (2018): Quality Improvement Initiative to Improve Postoperative Pain with a Clinical Pathway and Nursing Education Program,Pain Management Nursing, 19 (5), 447-455. 
13.P. Stein, G., Lieskovsky, R., (2016): cote, Radical cystectomy in the treatment of invasive bladder cancer ; journal of clinical oncology , vol .19, no 3, pp . 666-675,

14. ReRichards, B., Sebastian, B., Sullivan, H., Reyes, R., D'Agostino, J., \&Hagerty, T., (2017): Decreasing catheter-associated urinary tract infections in the neurological intensive care unit: One unit's success. Critical care nurse, 37 (3), 42-48.

15. Samineni, V., Mickle, A., Yoon, J., GrajalesReyes, J., Pullen, M., Crawford, K., \& Rogers, J., (2017): Optogenetic silencing of nociceptive primary afferents . Scientific reports, 7 (1), 15865.

16. Sharaf, M., (2018): Effect of Implementing a Nursing Management protocol on the postoperative Health outcomes for patients Undergoing Radical Cystectomy with Urinary Diversion Doctorate of Nursing science, faculty of Nursing ,Alexandria university p.p:21-25.

17. Soaad, A., (2016): Impact of educational program on nurses' knowledge and practices about arrhythmias for congestive heart failure patients master thesis critical care Nursing ,faculty of Nursing Assuit university p.p 82-84.

18. Standfuss C., (2012): Nurses' Knowledge of heart failure education topics at a regional Midwestern Hospital ,Thesis Dissertations and Other Capstone projects pp215.

19. Urden, L., Stacy, K., Lough, M., (2016): Priorities in Critical Care Nursing, Elsevier Inc, 793-79.

20. Woodruff, D., (2016): Critical Care Nursing made Incredibly Easy, Walters Kluwer Health, 109- 112. 